The opposite effects of routine metabolic rate and metabolic rate during startle responses on variation in the predictability of behaviour in hermit crabs

\title{
Velasque, $\mathrm{M}$
}

http://hdl.handle.net/10026.1/8060

10.1163/1568539X-00003371

Behaviour

Brill

All content in PEARL is protected by copyright law. Author manuscripts are made available in accordance with publisher policies. Please cite only the published version using the details provided on the item record or document. In the absence of an open licence (e.g. Creative Commons), permissions for further reuse of content should be sought from the publisher or author. 
The opposite effects of routine metabolic rate and metabolic rate during startle responses on variation in the predictability of behaviour in hermit crabs

Mariana Velasque

Mark Briffa

Correspondance: mariana.velasqueborges@plymouth.ac.uk

This is a manuscript of an accepted article published by Brill in Behaviour (2016), available at DOI 10.1163/1568539X-00003371 


\begin{abstract}
Studies on animal behaviour have suggested a link between personality and energy expenditure. However, most models assume constant variation within individuals, even though individuals vary between observations. Such variation is called intraindividual variation in behaviour (IIV). We investigate if IIV in the duration of the startle response is associated with metabolic rates (MR) in the hermit crab Pagurus bernhardus. We repeatedly measured startle response durations and MR during each observation. We used double hierarchical generalized linear models to ask whether among and IIV in behaviour was underpinned by MR. We found no association between the mean duration of the startle responses and either routine MR or MR during startle response. Nevertheless, we found that IIV increased with MR during startle responses and decreased with routine MR. These results indicate that crabs with higher MR during startle responses behave less predictably, and that predictability is reduced during exposure to elevated temperatures.
\end{abstract}

\title{
Introduction
}

In many species individuals differ in their behaviour consistently over time and these differences are often maintained across situations (Gosling \& John, 1999; Sih et al., 2004b; Réale et al., 2007; Briffa \& Greenaway, 2011). Some individuals, for example, are consistently bolder (e.g. Brown \& Braithwaite, 2004; Magnhagen \& Borcherding, 2008; Bridger et al., 2015), more aggressive (Bell, 2007; Sih \& Bell, 2008) or more cooperative (Bergmüller \& Taborsky, 2007; Charmantier et al., 2007; Schürch \& Heg, 2010) than other individuals from the same population. Such consistent among-individual behavioural variation is termed 'animal personality' (Gosling, 2001; Drent et al., 2003; Dingemanse \& Reale, 2005; Reale et al., 2007) and it seems to be ubiquitous in nature, ranging from humans 
to invertebrates (Gosling \& John, 1999; Sih et al., 2004b; Reale et al., 2007; Briffa \& Greenaway, 2011).

Several methods have been used to estimate such behavioural consistency, but the estimation of the 'broad sense' (as defined by Biro \& Stamps, 2015) repeatability, which is the most widely used measure of repeatability (Hayes \& Jenkins, 1997; Bell et al., 2009; Biro \& Stamps, 2015). In general, repeatability values tend to be low to moderate $(0.37-0.42$; Bell et al., 2009). Thus, most variation in behaviour is unaccounted for as consistent interindividual differences. One possibility for this is that unaccounted for environmental factors may contribute to variation in behavioural traits, so as to 'mask' the true amount of variation among individuals (e.g. Briffa \& Greenaway, 2011). Another possibility is that significant amounts of variation occurring within, rather than between individuals (Bell et al., 2009; Biro \& Stamps, 2015). Since repeatability (R) is the proportion of total variance (variance between individuals $\left[V_{\mathrm{BI}}\right]+$ variance within individuals $\left.\left[V_{\mathrm{WI}}\right]\right)$ that is due to between individual differences (i.e. $\left.\mathrm{R}=\mathrm{V}_{B I} /\left(V_{B I}+V_{\mathrm{WI}}\right)\right)$, overall estimates of repeatability do not provide direct information on the individual variance components. Thus, recent studies have focussed on understanding what factors may influence the within individual or 'intra-individual variance' component (IIV) (Nesselroade, 1991; Siegler, 1994; Salthouse, 2007; Ram \& Gerstorf 2009; Stamps et al., 2012; Briffa et al., 2013). This IIV is also sometimes referred to as predictability or individual consistency. In this case, individuals with a higher predictability will have lower IIV scores. Such studies have demonstrated that IIV is an important component of animal behaviour that seems to be related to learning (Maye et al., 2007; MacDonald et al., 2009; Bielak et al., 2010; Brembs, 2011), coping with risk (Briffa, 2013), male dominance and sexual selection (Cowlishaw, 1996; Rogers \& Cato, 2002; Delgado, 2006). 
In general, studies on animal personality have been revealing links between behavioural types (mean behaviour) and the pace of life syndrome (POLS; e.g. Smith \& Blumstein, 2008; Bell et al., 2009; Reale at al., 2010; Garamszegi et al., 2012; 2013; Urszán et al., 2015b). The POLS hypothesis aims to explain variation in life-history strategies and physiological traits, which are assumed to be expressed along a slow-fast continuum (Hille \& Cooper, 2015). Individuals that follow a slow POLS are expected to be long-living, avoid risk, be less active and with a lower metabolic rate (MR). In contrast, those with a fast POLS are expected to be more active, take more risks, be more aggressive and have a higher MR (e.g. "live fast and die young"; Biro \& Stamps, 2008; Smith \& Blumstein, 2008; Réale et al., 2010). Thus, variation in the pace of life might represent an underlying mechanism for animal personality variation (Careau \& Garland 2012), both in terms of among individual differences in mean level behaviour and in terms of among individual differences in behavioural consistency or IIV.

So far, studies investigating the link between behavioural traits and POLS have focussed on mean-level differences in behaviour, and taken together they indicate that the relationship between pace of life and animal personalities varies among study systems. In the deer mice (Perumyscus maniculatus) Careau et, al. (2011) found a positive relationship between exploration and MR. Similarly, more exploratory individuals of the superb fairywren (Malurus cyaneus) were less likely to be found 12 months later, indicating that these individuals are less long-lived. In contrast, the brown trout, Salmo trutta, seems to have a negative relationship between activity levels and mortality, indicating that longevity is not necessarily reduced in active individuals (Adriaenssens \& Johnsson, 2013). This lack of consensus between studies, may indicate the presence of an overlooked element. In fact, in recent meta-analysis Réale et al. (2010) found that two-thirds of the behavioural variation occurs within individuals rather than between individuals. Furthermore, recent studies 
focussing explicitly on the analysis of IIV, showing that predictability can consistently vary among individuals (i.e. IIV itself is repeatable; Biro \& Adriaenssens, 2013), as well as at the mean level. Taken together, these results suggest that IIV might play a key role in both natural and sexual selection and thus, be linked with POLS (Urszán et al., 2015b).

It seems logical, then, that variation in metabolic rate might drive among-individual variation in behaviour both at the individual-mean level and at the level of among individual variation in IIV (Careau et al., 2008; Houston, 2010). Nevertheless, studies investigating relationships between metabolism and IIV are still rare (Mathot \& Dingemanse, 2015). In the case of ectothermic marine invertebrates, metabolic rate is known to be driven by the temperature of the seawater. Thus, it is possible that individual consistency could be also dependent upon fluctuations in seawater temperature, if MR influences IIV. In the European hermit crab, Pagurus bernhardus, there is some evidence that startle response durations (where crabs hide in their empty gastropod shell upon disturbance, see below) increase at higher temperatures, although this effect was modified by treatment order (Briffa et al., 2013). There was, however, a clearer effect at the level of IIV, with crabs at a higher temperature treatment behaving less consistently (i.e. showing greater IIV) than those subjected to lower temperature, across a $5^{\circ} \mathrm{C}$ temperature difference. Thus, individuals that presumably had higher metabolic rates (due to elevated temperature) showed greater withinindividual variance in behaviour than those with lower metabolic rates.

One potential interpretation of this result is that individuals with high rates of metabolism have relatively high energy demands and therefore might be exposed to greater predation risk due to the need to service these energy demands through foraging (Briffa et al., 2013). Behaving less predictably might be a way to minimise these risks, and indeed $P$. bernhardus appear to behave less consistently in the presence of a predator (Briffa, 2013). Here, we directly investigate the links between metabolic rate and the duration of startle 
responses in the European hermit crab, while accounting for small fluctuations in temperature in the laboratory and for variation in crab mass. Hermit crabs occupy empty gastropod shells and a simple stimulus causes them to withdraw from their shells and slowly re-emerge. The latency to emerge from the shell ('startle response duration') is considered a measure of 'boldness' (Biro \& Stamps, 2008; Briffa et al., 2013; Bridger et al., 2015) and its variation between and within-individuals is well studied in this species (Briffa, 2013; Briffa et al., 2013; Bridger et al., 2015). To avoid indirect associations between MR and the behavioural trait (Mathot \& Dingemanse, 2015), we repeatedly measured the oxygen consumption in two situations: during routine behaviour (routine MR) and during the startle response period, where crabs are withdrawn into their shells (startled MR). We considered startled MR as the metabolic rate of a reactive individual during and after the application of a stimulus. Routine MR is defined as the metabolic rate of an undisturbed, post-absorptive, resting individual, it also includes some level of random activity, maintenance of equilibrium and posture (Jobling, 1994; Killen et al., 2011; Mathot \& Dingemanse, 2015).

Here we investigate the links between metabolic rate and boldness analysed across two levels, individual mean boldness and within-individual variation in boldness (IIV). In addition to variation in metabolic rate we also analyse the effects of small (uncontrolled) fluctuations in temperature within the laboratory, since these could influence both metabolism and oxygen availability. We predicted that the MR would have a negative correlation with the duration of the startle response at the mean level of behaviour and in IIV of behaviour. In other words, according to the POLS hypothesis, we should expect individuals with a high metabolic rate to recover quickly from a perturbation and hence show startle responses of relatively short duration. Furthermore, if shorter startle responses equate to greater risk exposure, we would expect individuals with higher metabolic rate to show relatively low levels of behavioural consistency, and hence high levels of IIV. 


\section{Materials and methods}

\section{Collection and maintenance of hermit crabs}

We collected hermit crabs between November 2013 and January 2014 from the rocky intertidal at Hannafore Point, Cornwall, UK $\left(50^{\circ} 20^{\prime} \mathrm{N},-4^{\circ} 27^{\prime} \mathrm{W}\right)$, from where they were transported directly back to the laboratory at Plymouth. In the laboratory we removed crabs from their shells by cracking in a bench vice. This stage is necessary because the behaviour of hermit crabs, including the duration of the startle response, could be affected by the shell mass (Briffa \& Bibost, 2009). All crabs thus received a new Littorina littorea shell with $100 \%$ of its preferred mass (Briffa \& Elwood, 2007). We only used male crabs (mean mass $=$ $0.76 \mathrm{~g} \pm \mathrm{SE}=0.34 \mathrm{~g})$ free from obvious parasites, appendage damage or recent moult $(\mathrm{N}=40)$. Crabs were individually housed in white plastic dishes of $16 \mathrm{~cm}$ of diameter, filled to $4 \mathrm{~cm}$ depth with seawater, with continuous aeration and feed daily ad libitum with cubes of white fish at the end of each observation (i.e. there was always excess food available in the housing dishes, outside of the observation periods). The seawater was from our laboratory supply, which is regularly obtained from the seaward side of Mount Batten pier $\left(50^{\circ} 36^{\prime} \mathrm{N},-4^{\circ} 13^{\prime} \mathrm{W}\right)$ in Plymouth Sound, at spring tides. They were acclimated for ten days in a temperature controlled room (mean temperature $=12.21^{\circ} \pm \mathrm{SE}=1.05^{\circ} \mathrm{C}$ ), followed by a ten days of daily observation of startle response durations (see below).

\section{Determination of routine and active metabolic rate}

We determined the routine and startled metabolic rate for each crab using the oxygen uptake as a proxy (Dupont-Prinet et al., 2010). This was measured daily using a sealed 'Kilner' jar (polyethylene terephthalate, PET), blackened-out and a non-invasive optical oxygen sensor with a temperature probe (OxySense GEN III 5000 series, OxySense, Dallas, TX). Each jar 
had a sensor spot attached on the inner wall with silicone glue. The sensor spot reacts with the oxygen present inside the jar and, when read by the sensor, shows the remaining concentration of $\mathrm{O}_{2}$, allowing a non-invasive measurement (a closed respirometer). We closed the jar underwater using a rubber washer to ensure the absence of air bubbles. To prevent oxygen stratification and ensure moderate mixing of water, we placed the jar onto a multi-channel magnetic stirrer (MIX 15 eco; 2mag AG, Munich, Germany) with a magnetic flea inside. A mesh was placed between the hermit crab and the magnetic flea to ensure no contact. In order to control for possible bias from algal or bacterial activity in oxygen measurements, we only used filtered seawater. Additionally, oxygen measures can also be influenced by the jar material, as some types of plastic can absorb or release oxygen (Stevens, 1992) (although significant $\mathrm{O}_{2}$ exchange is less likely with the high quality PET material that we used here, compared with other plastics). Therefore, to account for both microbial activity and potential oxygen exchange with the jar material, we measured the oxygen consumption in two extra jars containing the same seawater used in the experiments and one empty $L$. littorea shell ("blank") similar to those occupied by the crabs. We then accounted for any microbial activity and any the effect of the jar's material in the final calculation of metabolic rate (Calosi, et al., 2013).

We allowed hermit crabs rest for 15 minutes of resting before starting routine MR measures of oxygen consumption. To allow an accurate estimation of oxygen concentration inside the jar we obtained readings every 5 minutes, during 25 minutes (i.e. 5 measures of $\mathrm{O}_{2}$ concentration in total per estimate). These measures were then used to estimate the rate of $\mathrm{O}_{2}$ uptake by the hermit crab (see below for the calculation). Previous observations indicate a stabilization of oxygen consumption after 15 minutes of resting, and therefore, a minimization of stress imposed by the manipulation.

We then recorded the startled MR immediately after the routine MR. We obtained the 
startled MR measurements immediately after inducing a startle response (Briffa et al., 2008; Stamps et al., 2012). As previously stated, we considered startled MR as the metabolic rate of an individual during and after a stimulus, thus we measured startled MR and startle responses simultaneously. In the current study, where crabs are housed in sealed jars for the measurement of metabolic rate, it was not possible to induce startle responses in the same way as previous studies by manually handling the crabs. This is because the manual handling procedure would entail opening the respirometry jar and then resealing it after the response had been induced. These procedures would lead to (a) a time delay in the onset of measurements of oxygen concentration and (b) the potential for additional disturbance to the crabs (e.g. unintentional movements of the jar during resealing) that would be difficult to quantify. Therefore, we used an alternative technique where the startle response was induced by carefully lifting the jar (avoiding early disturbance to the crab) by $30 \mathrm{~cm}$ and then releasing it so that it fell back onto the bench. This induced hermit crabs to withdraw into their gastropod shells in a similar way to the manual handling technique used in previous studies, with the vast majority of crabs falling into an aperture facing upwards position following the drop. Furthermore, the use of a physical impact on the jar is similar to an approach used in other studies of hermit crabs where an object has been dropped onto the top of an unsealed crystallising dish to induce startle responses (see Elwood \& Briffa, 2001; Briffa \& Elwood, 2001). Initial observations indicated that when aligned in a horizontal position and dropped from $30 \mathrm{~cm}$, the jar will rarely spin or bounce when hits the bench, independent of the hermit crab position inside the jar. When it occurs, routine MR measures and the startle response induction were made after two hours of rest.

We timed the latency of recovery from the point at which the jar is released to the point at which the perieopods first make contact with base of the jar. As the startle response varies among and within individual hermit crabs it was not possible to measure oxygen 
concentrations over a set time period as in the case for our estimate of routine MR. Instead we measured the oxygen concentration inside the jar at a higher time resolution of every five seconds. These measurements commenced at the point at which the hermit crab withdrew into its shell and continued until five minutes after its recovery. These repeated measures of oxygen concentration were then used to estimate the rate of oxygen uptake during and following the startle response (see below for calculation).

We obtained 10 startle response durations along with 10 measures of Routine MR and startled MR for each of 40 individuals yielding 400 observations in total. Measures made using closed respirometers are never constant due to the continuous use of oxygen by the organisms inside the jar. Thus, we used the decrease in oxygen concentration to calculate the $\mathrm{O}_{2}$ consumption per individual. In humid environments the oxygen consumption is dependent on the oxygen solubility, which in turn is dependent on both temperature and salinity. Although we conducted measures in temperature controlled rooms, small fluctuations still occurred, which could affect both behaviour and oxygen consumption rates. We calculate the $\mathrm{O}_{2}$ consumption rate using the slope from a linear regression of oxygen consumption over time minus the blank variations. The slope was then multiplied by the oxygen solubility coefficient (adjusted for salinity and temperature). Thus, rate of $\mathrm{O}_{2}$ consumption was calculated using

$$
\text { Rate of } \mathrm{O}_{2} \text { uptake }\left(\mu \text { moles } \mathrm{O}_{2} \mathrm{~h}^{-1}\right)=C(t) \times\left(V_{r}\right) \times\left(60 / t_{1}-t_{2}\right)
$$

Where, $\mathrm{C}(\mathrm{t})$ is the $\mathrm{O}_{2}$ consumption rate (from the linear regression of oxygen consumption over time), $\mathrm{V}_{\mathrm{r}}$ is the total volume of water inside the jar (jar volume minus the hermit crab volume) and $\mathrm{t}_{0}, \mathrm{t}_{1}$, is the measurement period (in minutes; Widdows \& Staff, 2006; Calosi, et al., 2013). To create a standardized measures and allow comparisons between individuals, we divided the rate of $\mathrm{O}_{2}$ uptake by the individual body mass (without the shell; Porter \& Brand, 1995). 


\section{Data analysis}

Previously, mean level behaviour and IIV have been calculated using general linear-mixed effects model (GLMM) in a two-step analysis. First, a random regression model is fitted (Stamps et al., 2012; Briffa et al., 2013; Cleasby et al., 2015). With this model it is possible to obtain the expected values, followed by the residual individual standard deviation (riSD). Although widely used in human personality, and recently animal personality, research this method has some limitations (Cleasby et al., 2015; Bridger et al., 2015). GLMMs assume homoscedastic residual variation in behaviour (the same for all individuals), which is violated if individuals do indeed differ in IIV (Bridger et al., 2015; Cleasby et al., 2015). Secondly, a two-step analysis might inflate type 1 errors, by not carrying forward the uncertainty estimates from step 1.

More recently (e.g. Bridger et al., 2015) an alternative approach has been used, where the mean and the variance for each individual are modelled iteratively using hyperparameters. These models are extensions of GLMM called hierarchical GLMs (HGLM). HGLMs models sets of interlinked GLMs, allowing parameters non-normally distributed (Lee \& Nelder, 1996). Additionally, such models allow the specification of separate models for the mean and standard deviation model (SD model), both incorporating fixed and random effects. Such models are termed Double HGLM (DHGLM; Lee \& Nelder, 2006). We used the software ASReml-R (Butler et al., 2009) in R version 3.2.1 (R Development Core Team, 2012) to fit a DHGLM model, as follows.

In the mean model we included observation number, mass, routine and startled metabolic rate as fixed effects. As we had small temperature variations, we also include temperature as a fixed effect (covariate) to account for this. We modelled a random intercept and a random slope effect to allow for among individual variation in responses to repeated 
observations (see supplementary material for detailed descriptions). We tested for correlation between all fixed effects and none were significant (see supplementary material for detailed descriptions). In the SD model we included mass, temperature, routine and startled metabolic rate as fixed effects, and random intercepts for each individual (random slopes are not possible in the SD model because we only obtained one set of repeated measures within per individual, allowing a single estimate of residual variance; see supplementary material for detailed descriptions). As the model is expected to be robust against outliers (Lee \& Nelder, 2006), we opted to use non-transformed data. We used Wald-F test to test the significance of fixed effects and z-ratio for random.

\section{Ethical note}

No animals were harmed during the experiment and at the end of the experiment all individuals appeared healthy and were supplied with excess food (as above) and a new gastropod shell before being returned to the sea.

\section{Results}

The mean startle response duration did not vary with either routine $\left(\chi^{2}{ }_{1}=0.41, p=0.5227\right)$ or startled $\left(\chi^{2}=0.06, p=0.8140\right)$ metabolic rate, and there was no significant effect of either mass $\left(\chi^{2}=0.24, p=0.6227\right)$ or temperature $\left(\chi^{2}=1.20, p=0.27\right.$; Table 1$)$ on the startle response duration. There was, however, a clear pattern of reduction in startle response duration across successive observations $\left(\chi^{2}=18.89, p=0.02617\right.$, Table 1), indicating habituation. A significant random intercept indicated that there was among individual variation in the mean startle response duration $\left(\chi^{2}=11.37, p=0.0006\right.$, Table 1$)$.

In the standard deviation model, the analysis of the fixed effects indicates that IIV in startle response duration increases with temperature $\left(\chi^{2}=28.9, p<0.001\right)$ and with startled 
metabolic rate $\left(\chi^{2}=10.4, p=0.00062\right)$ but decreases with crab mass $\left(\chi^{2}=25.1, p<0.001\right)$ and with routine metabolic rate $\left(\chi^{2}=55.4, p<0.001\right.$; Table 1 ; figure 1$)$. In summary, crabs behave more consistently when exposed to higher average temperatures and if they have a high metabolic rate during the startle response. In contrast, crabs that were large or had a higher routine MR showed an increasing of consistency in startle response duration.

The random intercepts of the mean and SD model indicate the presence of significant within-individual variation, but not significant between-individual variation (Table 2). To provide a standardised measure of the proportion of variance due to between individual variation in behaviour we also calculated the repeatability $\left(R_{\mathrm{c}}\right.$; Biro \& Stamps, 2015) of startle responses and both routine and startled MR. For each variable, we fitted a model on only a constant (intercept) and the observation as a fixed effect and the individual's ID as random effect (Wilson et al., 2010). The significance of repeatability was obtained using a likelihood ratio test (LRT) method, which compares the likelihoods of the linear mixed model described above (with the individual's ID as a random effect) and a general linear model without random effect (Nakagawa \& Schielzeth, 2010), distributed as Chi square with one degree of freedom. The repeatability of the startle response was $0.013\left(\mathrm{X}^{2}=28.33\right.$, $\mathrm{p}<0.001)$. Since it is not possible to directly generate confidence intervals around this estimate of repeatability obtained from the variance components of our model, and to allow comparison with other studies where data on traits such as MR are absent, we also calculated an unadjusted (in relation to the model fixed effects) repeatability, based on a linear mixed model. Here the repeatability was $R_{\mathrm{LMM}}=0.111 \pm \mathrm{SE}=0.042(95 \% \mathrm{CI}=[0.034,0.193], \mathrm{P}<$ $0.0001)$. The repeatability of the routine MR was $0.00133\left(\mathrm{X}^{2}=61.26, \mathrm{p}<0.001\right)$ and startle MR was $0.00006\left(\mathrm{X}^{2}=1.91, \mathrm{p}=0.166\right)$. 


\section{Discussion}

Previous studies highlighted the importance of investigating intra-individual variance in behaviour in addition to the mean level (Briffa, 2013; Brommer, 2013; Dingemanse \& Dochtermann, 2013; Bridger et al., 2015). In the hermit crab Pagurus bernhardus, we found that body mass, temperature, routine and startled metabolic rate had no relationship in the mean duration of the startle response, and thus, contrary to our prediction, boldness in $P$. bernhardus does not appear to be related with POLS. However, we found a significant relationship between IIV in startle response and these life history traits (body mass, temperature, routine MR and startled MR). Additionally, $P$. bernhardus also exhibited a higher intra-individual variation in behaviour than between-individual variation, consistent with a previous meta-analysis (Bell et al., 2009). Behavioural traits, in general, have low to moderate repeatability (0.37-0.42; Bell et al., 2009), which has been shown in previous studies in P. bernhardus (e.g. Stamps et al., 2012; Briffa, 2013; Briffa et al., 2013). In this study, however, although there was significant repeatability (i.e. 95\% CIs did not cross zero) our estimates were much lower than for those previous studies on the same species. One possible explanation for the lower repeatability is the method used to stimulate the startle response. As the startle response is associated with defence, being manually handled (e.g. Stamps et al., 2012; Briffa, 2013; Briffa et al., 201) could be a less intense stimulus for hermit crabs and thus, result in a more predictable response than a free fall of $30 \mathrm{~cm}$. Furthermore, a recent study on tadpoles of the frog Rana dalmatina has shown that novel stimuli might yield lower repeatability compared to stimuli that the animal is likely to be more familiar with (Urszán et al. 2015a). Hermit crabs are frequently perturbed in their habitat (due to wave action, encounters with predators or indeed with other hermit crabs), which is simulated by the manual handling protocols used in previous studies. In contrast, they are unlikely to experience frequent $30 \mathrm{~cm}$ falls. Nevertheless, this approach was 
necessary in order to obtain respiration rates during recovery form disturbance and this technique still resulted in significant repeatability, allowing analysis of the variance components of interest.

Several studies have documented the repeatability of metabolic rate across several taxa taxa (McCarthy, 2000; Broggi et al., 2007; Nespolo \& Franco 2007). So far, metabolic rate appears to be a repeatable trait (Nespolo \& Franco 2007), with a potentially stable state (Konarzewski et al., 2005) and linked to the activity level (Nespolo \& Franco 2007; SundtHansen et al., 2009). Nevertheless, such studies are mainly focussed on endotherms (for review see Nespolo \& Franco 2007), and by having a higher self-maintenance cost, tend to have a higher and more constant metabolic rate (basal metabolic rate; Stearns, 1992). While invertebrates, by being ectothermic, are strongly influenced by ambient temperature and, in general, show lower metabolic rates, even in activity (Alexander, 1999; Nespolo \& Franco 2007). Those differences could explain the lower repeatability estimate in routine MR, as it was measured with minor temperature variation and with some random levels of hermit crab activity. And, in hermit crabs, such uncontrolled environmental variance combined with an unnatural method to stimulate the startle response (by dropping), may generate lack of repeatability in startled MR.

Indirect associations between behaviour and POLS have been largely criticized (e.g. growth-related traits) with the suggestion that direct associations between behaviour and metabolic rate are required for adequate testing of the POLS hypothesis (Adriaenssens and Johnsson, 2009). Although logical, such correlations have a mixed support (e.g Bryant \& Newton, 1994; Ketola \& Kotiaho, 2012; Krams et al., 2013). Mathot and Dingemanse (2015) suggested that studies attempting to link metabolic rate and behaviour may be biased if metabolic rate is measured in only on one (or a few) occasions. This is because a single measure of metabolic rate may be insufficient to infer results regarding the energy 
management of individuals. In our study, however, we measured both types of metabolic rate (routine MR and startled MR) repeatedly with measures of MR being taken immediately prior to and coinciding with each behavioural observation. With this large amount of data, we nevertheless failed to observe any association between mean startle response duration and either routine MR or startled MR. In contrast, we found a significant association with IIVlevel variation in startle responses. Contrary to our prediction, our results indicate a negative correlation between IIV and routine MR, indicating that individuals showing low levels of consistency are those with the lower routine metabolic rates. In contrast, individuals with low levels of consistency had higher metabolic rates during startle response.

Despite the POLS predicting a positive relationship between activity, superficial exploration and energetic expenditure, there is no consensus on its prediction regarding within individual variation in behaviour (Coppens et al., 2010; Careau et al., 2012; Niemelä et al., 2012b). Coppens et al. (2010) and Niemelä et al. (2012b) for example, suggested that a fixed behavioural strategy (lower IIV) should be less energetically demanding (due to lower costs for cognitive activities) and thus more common in slow-paced strategy individuals. Urszán et al. (2015a) found similar results, and a positive relationship between gain in mass and low IIV in exploratory behaviour in tadpoles (Rana dalmatina). Our results, however, indicate that in P. bernhardus the POLS strategy may be conditional on behavioural consistency.

Individuals with low routine MR were those that subsequently revealed high IIV variability in startle response durations. Conversely, startled MR increased with IIV. Thus in the context of linking metabolic rate to ideas about the pace of life, both the situation in which metabolic rate is estimated and the level of behavioural variation under analysis appear critical. Indeed, Mathot \& Dingemanse (2015) point out that both behaviour and physiological traits are highly flexible, and thus, any slow-fast classification of individuals 
must be carefully assessed in more than one situation. In P. bernhardus the variability in hiding time seems to be a strategy to cope with risk (Briffa et al., 2013; Briffa, 2013). Our results reinforce such findings, since the startled MR was only correlated in the IIV level, and not in the mean-level. Therefore, it appears that, at least in potentially stressful situations, within-individual variation in behaviour, rather than individual mean levels of behaviour, might be linked with underlying variation in metabolic rate (Dall et al., 2004).

Habituation is a type of learning in which an individual after repetitive stimulation exhibits a waning of its response (Thorpe, 1956). It occurs when a continued response to a nonthreatening stimulus is considered to be energetically costly (Raderschall et al., 2011). Previous investigations in P. bernhardus, however, have did not detect any habituation (Briffa et al. 2008; Briffa et al., 2013; Bridger et al. 2015). Our study demonstrates a mean level reduction in startle response duration with observation, and thus habituation with the startle response stimulation. One possible explanation is the way in which we induced the startle response. As habituation is described to occur faster with weaker stimuli (Rankin et al., 2009), it is possible that the dropping stimulus is less intense than manually handling, generating habituation and thus a lower (but still significant) repeatability in startle response.

Previous studies in P. bernhardus have shown that the mean-level boldness is sensitive to ambient temperature. Hermit crabs when transferred to a different temperature treatment $\left(10^{\circ} \mathrm{C}\right.$ to $15^{\circ} \mathrm{C}$ and $15^{\circ} \mathrm{C}$ to $\left.10^{\circ} \mathrm{C}\right)$ had a significant increase in mean-level boldness (Briffa et al., 2013). In contrast to that study where temperature was manipulated, in the current experiment we attempted to make observations across stable temperature conditions. Hence, the temperature variation during the current experiment was much lower, and maybe insufficient to generate a general trend in mean level behaviour. Nevertheless, at the IIV level these relatively small and routine temperature fluctuations appear to have been sufficient to generate a relatively strong positive effect. Individuals seemed to exhibit a higher variation in 
behaviour when exposed to higher temperatures. This result is consistent with the hypothesis that an increase in temperature, in poikilotherms, could result in increasing in the unpredictability in behaviour (Dingemanse et al., 2010; Briffa, 2013). However, we did not find any clear correlation between routine MR or startled MR and the temperature of the seawater, indicating that the small temperature fluctuations experienced during the experiment were not sufficient to drive changes in metabolic rate (see supplementary material for detailed descriptions). Therefore, it is interesting that temperature appears to have a greater effect on IIV compared to either measure of MR. A possible explanation is that at greater temperatures poikilothermic predators may be more active (Petersen \& Kitchell, 2001). However, we also note that a direct interpretation of the effects of temperature in this study may be less easy to interpret in comparison where temperature variation was specifically manipulated across a wider temperature range (e.g. Briffa et al. 2013). Since the small fluctuations in temperature occurred within and between observations it is unlikely that the animals were in a steady temperature state.

We also found that the mean duration of the startle response in P. bernhardus have had no relationship with the hermit crab body mass, similar to other studies (Briffa et al., 2008; Bridger et al., 2015). But, it appears to have a strong negative effect on the IIV level. Heavier individuals, were the ones with lower IIV. Growth in crustaceans is a step-wise process, resulting from sequential moulting (Liberto \& Mesquita-Joanes, 2014), and in the case of hermit crabs it is further constrained by access to suitable gastropod shells. Although it could be influenced by several factors (e.g. sex and environmental conditions during ontogeny), size, in general, varies with age (size-age relationship; Liberto \& Mesquita-Joanes, 2014) so here it may be the case that IIV decreases with age.

Although there is not much consensus on why animals vary in the predictability of their behaviour, a few studies have shown that IIV reduces with age and previous experience 
(Maye et al., 2007; Brembs, 2011; Urszán et al., 2015b). If so, IIV could represent adaptive stochastic variation in behaviour, facilitating trial and error learning (Brembs, 2011). That is possible because individuals tend to adjust their behaviour according to environmental conditions and internal state (behavioural plasticity; Briffa, 2013). However, such behavioural flexibility is likely to be costly (as we demonstrated; Dall et al., 2004; Careau et al., 2008), and thus, individuals tend to develop a behavioural strategy that becomes less flexible with age and previous experience (Dall \& Cuthill, 1997; Dall et al., 2004). In contrast, Bridger et al. (2015) found that IIV in hermit crabs increases with mass. Although both studies investigate the variation in startle response in P. bernhardus, Bridger et al. (2015) induced the startle response by lifting and replacing the hermit crabs at the base of the tank, while here we dropped the jar causing the animal to withdraw inside the shell. Nevertheless, we obtained a similar relationship between the mean duration of the startle response and crab weight (Briffa et al., 2008; Bridger et al., 2015), indicating that the method variation may not be the responsible by such conflicting results. An alternative explanation is that Bridger et al. (2015) controlled for mass, using lighter crabs across a smaller size range, which could hide effects of ontogenetic variations in behavioural trends (Bridger et al., 2015). In studies of IIV in hermit crabs to date, we have used hermit crabs from a single size class, as defined by the species of gastropod shell that they occupy. Further studies, using hermit crabs form different size classes, which are distinct due to the different species of gastropod shell that crabs of markedly different sizes occupy, would enable us to gain further insights into how IIV varies with age.

Studies on animal personality have increased over the last decade. They have investigated the maintenance of a given behavioural trait over time, situation, across environmental conditions (Sih et al., 2004; Bell \& Sih, 2007; Réale et al., 2007; Cote et al., 2008). However, the knowledge behind physiological and behavioural correlations in both 
mean level behaviour and IIV still is in early stages (Fresneau et al., 2014), mainly due to the lack of statistical tools to divide the variance into mean and IIV levels (Cleasby et al., 2015). Our findings demonstrate that relationships between behavioural traits and underpinning physiology can be variable within individuals, dependent on current activity rates.

Table 1- The fixed effects and their statistical significance of the mean model and for standard deviation model of the duration of the startle response.

\begin{tabular}{lllllll}
\hline Sub-model & Parameter name & Effect & SE & df & Wald $X^{2}$ & p-value \\
\hline Mean & Intercept & $\mathbf{9 6 . 9 9 9 8}$ & $\mathbf{1 1 3 . 2 6 9}$ & $\mathbf{1}$ & $\mathbf{1 1 . 3 6 9 9}$ & $\mathbf{0 . 0 0 0 5 5}$ \\
& Observation & $\mathbf{- 8 . 5 6 8 7}$ & $\mathbf{3 . 3 6 3}$ & $\mathbf{9}$ & $\mathbf{1 8 . 8 8 7 6}$ & $\mathbf{0 . 0 2 6 1 7}$ \\
& Mass & -22.1446 & 135.238 & 1 & 0.2421 & 0.62271 \\
& Temperature & 12.1099 & 42.623 & 1 & 1.1993 & 0.27346 \\
& Routine MR & -0.0155 & 0.475 & 1 & 0.4085 & 0.52272 \\
Variance & Intercept & $\mathbf{7 . 1 4 2 9 0 1}$ & $\mathbf{0 . 9 2 3 1}$ & $\mathbf{1}$ & $\mathbf{1 9 0 4 1 . 8}$ & $<\mathbf{0 . 0 0 0 1}$ \\
& Mass & $\mathbf{- 1 . 1 9 8 0 3}$ & $\mathbf{0 . 2 3 3 5}$ & $\mathbf{1}$ & $\mathbf{2 5 . 1}$ & $<\mathbf{0 . 0 0 0 1}$ \\
& Temperature & $\mathbf{0 . 3 9 2 0 1}$ & $\mathbf{0 . 0 7 2 9}$ & $\mathbf{1}$ & $\mathbf{2 8 . 9}$ & $<\mathbf{0 . 0 0 0 1}$ \\
& Routine MR & $\mathbf{- 0 . 0 0 5 1 1}$ & $\mathbf{0 . 0 0 0 7}$ & $\mathbf{1}$ & $\mathbf{5 5 . 4}$ & $<\mathbf{0 . 0 0 0 1}$ \\
& Startled MR & $\mathbf{0 . 0 0 2 2 9}$ & $\mathbf{0 . 0 0 0 7}$ & $\mathbf{1}$ & $\mathbf{1 0 . 4}$ & $\mathbf{0 . 0 0 0 6 2}$
\end{tabular}

(Mean effect sizes of factors and covariates with their effects, standard error, Wald's chi-square test and pvalues; significant variables are printed in bold).

Table 2- Estimated variance components for behavioural traits. $\sigma^{2}$ is the variance of each component. Statistical significance is assessed by comparing variance to the Z-Ratio; effects are considered to be statistically significant if $Z>2$ (Wilson et al., 2010). Significant variables are printed in bold.

\begin{tabular}{llll}
\hline Component & $\boldsymbol{\sigma}^{2}$ & SE & Z-Ratio \\
\hline Between-individual & 2122.309 & 3939.88 & 0.53868
\end{tabular}


Within-individual $\quad 43583.42 \quad 5653.985 \quad \mathbf{7 . 7 0 8 4 4 4 1}$

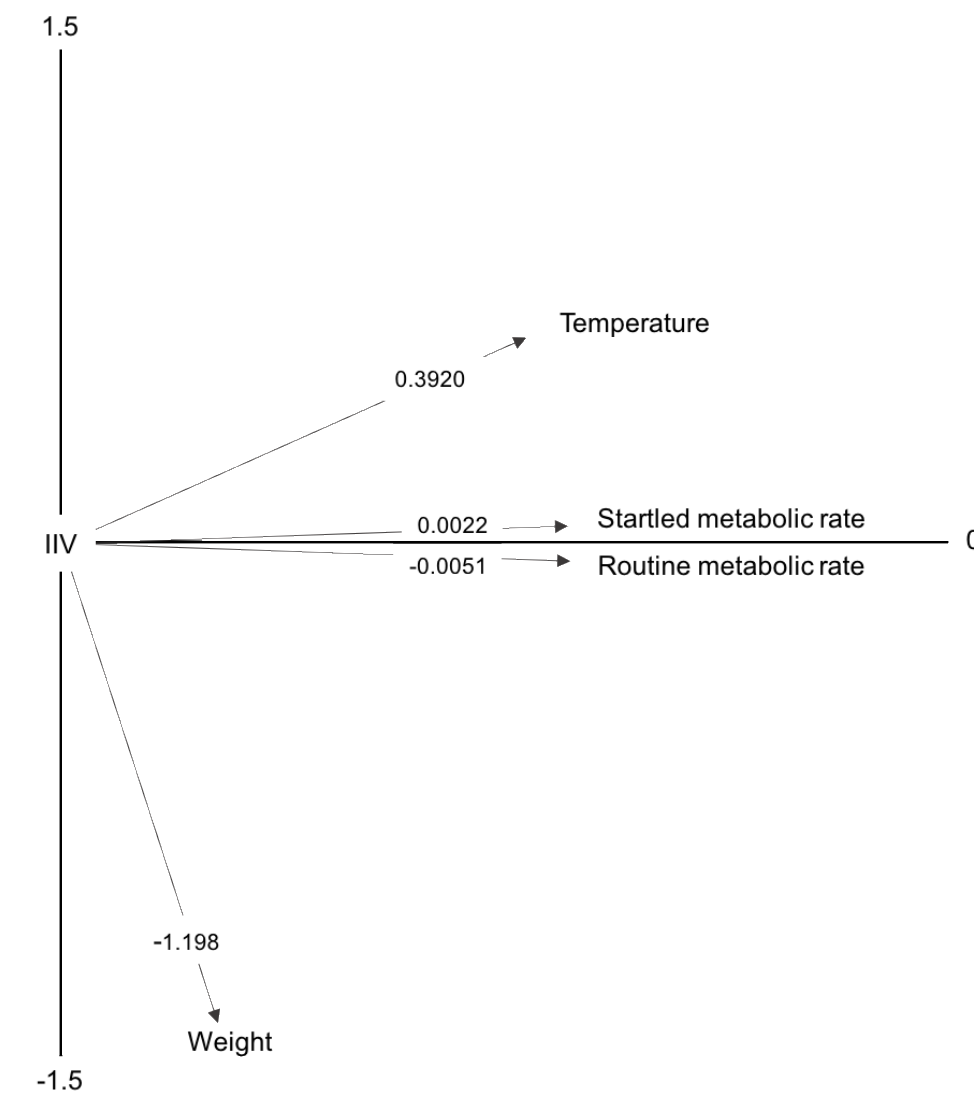

Figure 1- Representation of the effects of four parameters on IIV. Values were extracted from the standard deviation model on the DHGLM. The angle of the arrows represents the effect size of each parameter on IIV.

\section{Acknowledgements}

This research was supported by CAPES, Coordination for the Improvement of Higher EducationBrazil, Science Without Borders Program, CsF. We are also grateful to two anonymous reviewers, whose insightful comments have helped us to improve this study. 


\section{References}

Adriaenssens, B. \& Johnsson, J.I. (2010). Shy trout grow faster: exploring links between personality and fitness-related traits in the wild. -Behav. Ecol. 22:135-143.

Adriaenssens, B. \& Johnsson, J.I. (2013). Natural selection, plasticity and the emergence of a behavioural syndrome in the wild. -Ecol. Lett. 16: 47-55.

Alexander, R.M. (1999). Energy for Animal Life. Oxford University Press, New York.

Bell, A.M. (2007). Future directions in behavioural syndromes research. -Proc. R. Soc. Lond. B. Biol. Sci. 274:755-761.

Bell, A.M., Hankison, S.J. \& Laskowski, K.L. (2009). The repeatability of behaviour: a metaanalysis. -Anim. Behav. 77:771-783.

Bell, A.M. \& Sih, A. (2007). Exposure to predation generates personality in threespined sticklebacks (Gasterosteus aculeatus). -Ecol. Lett. 10:828-834.

Bergmüller, R. \& Taborsky, M. (2007). Adaptive behavioural syndromes due to strategic niche specialization. $-\mathrm{BMC}$ ecol. 7:12.

Bielak, A.A., Hultsch, D.F., Strauss, E., MacDonald, S.W. \& Hunter, M.A. (2010). Intraindividual variability is related to cognitive change in older adults: evidence for withinperson coupling. -Psychol. Aging. 25(3), 575.

Biro, P.A. \& Adriaenssens, B. (2013). Predictability as a personality trait: consistent differences in intraindividual behavioral variation. - Am. Nat. 182: 621-629.

Brembs, B. (2011). Towards a scientific concept of free will as a biological trait: spontaneous actions and decision-making in invertebrates. -Proc. R. Soc. Lond. B. Biol. Sci. 278:930-939. 
Biro, P.A. \& Stamps, J.A. (2008). Are animal personality traits linked to life-history productivity? -Trends Ecol. Evol. 23:361-368.

Biro, P.A. \& Stamps, J.A. (2015). Using repeatability to study physiological and behavioural traits: ignore time-related change at your peril. -Anim. Behav. 105:223-230.

Bridger, D., Bonner, S.J. \& Briffa, M. (2015). Individual quality and personality: bolder males are less fecund in the hermit crab Pagurus bernhardus. - Proc. R. Soc. B. 282:20142492.

Briffa, M \& Elwood, RW. (2001). Motivational change during shell fights in the hermit crab Pagurus bernhardus. -Anim. Behav. 62:505-510

Briffa, M. (2013). Plastic proteans: reduced predictability in the face of predation risk in hermit crabs. -Biol. Letters. 9:20130592.

Briffa, M. \& Bibost, A.L. (2009). Effects of shell size on behavioural consistency and flexibility in hermit crabs. -Can. J. Zool. 87:597-603.

Briffa, M., Bridger, D. \& Biro, P.A. (2013). How does temperature affect behaviour? Multilevel analysis of plasticity, personality and predictability in hermit crabs. -Anim. Behav. 86:47-54.

Briffa, M. \& Elwood, R.W. (2007). Monoamines and decision making during contests in the hermit crab Pagurus bernhardus. -Anim. Behav. 73:605-612.

Briffa, M. \& Greenaway, J. (2011). High in situ repeatability of behaviour indicates animal personality in the beadlet anemone Actinia equina (Cnidaria). -PLoS One. 6:e21963-e21963.

Briffa, M., Rundle, S.D. \& Fryer, A. (2008). Comparing the strength of behavioural plasticity and consistency across situations: animal personalities in the hermit crab Pagurus bernhardus. -Proc. R. Soc. Lond. B. Biol. Sci. 275: 1305-1311.

Broggi, J., Hohtola, E., Koivula, K., Orell, M., Thomson, R.L. \& Nilsson , J. (2007) Sources 
of variation in winter basal metabolic rate in the great tit . -Fun. Ecol., 21:528-533.

Brommer, J.E. (2013). On between-individual and residual (co) variances in the study of animal personality: are you willing to take the "individual gambit"? -Behav. Ecol. Sociobiol. 67:1027-1032.

Brown, C. \& Braithwaite, V.A. (2004). Size matters: a test of boldness in eight populations of the poeciliid Brachyraphis episcopi. -Anim. Behav. 68:1325-1329.

Butler, D.G., Cullis, B.R., Gilmour, A.R. \& Gogel, B.J. (2009). ASReml-R reference manual. VSN International Ltd, Hemel Hempstead, UK

Bryant, D.M. \& Newton, A.V. (1994). Metabolic costs of dominance in dippers, Cinclus cinclus. -Anim. Behav. 48:447-455.

Calosi, P., Turner, L.M., Hawkins, M., Bertolini, C., Nightingale, G., Truebano, M. \& Spicer, J.I. (2013). Multiple physiological responses to multiple environmental challenges: an individual approach. -Integr. Comp. Biol. 53:660-670.

Careau, V. \& Garland Jr, T. (2012). Performance, personality, and energetics: correlation, causation, and mechanism. -Physiol. Biochem. Zool. 85:543-571.

Careau, V., Thomas, D., Humphries, M.M. \& Réale, D. (2008). Energy metabolism and animal personality. -Oikos. 117:641-653.

Careau, V., Thomas, D., Pelletier, F., Turki, L., Landry, F., Garant, D. \& Réale, D. (2011). Genetic correlation between resting metabolic rate and exploratory behaviour in deer mice (Peromyscus maniculatus). -J. Evolution. Biol. 24:2153-2163.

Charmantier, A., Keyser, A.J. \& Promislow, D.E. (2007). First evidence for heritable variation in cooperative breeding behaviour. -Proc. R. Soc. Lond. B. Biol. Sci. 274:17571761.

Cleasby, I.R., Nakagawa, S. \& Schielzeth, H. (2015). Quantifying the predictability of 
behaviour: statistical approaches for the study of between-individual variation in the withinindividual variance. -Methods Ecol. Evol. 6:27-37.

Coppens, C.M., de Boer, S.F. \& Koolhaas, J.M. (2010). Coping styles and behavioural flexibility: towards underlying mechanisms. - Philos. T. Roy. Soc. B. 365:4021-4028.

Cote, J., Dreiss, A. \& Clobert, J. (2008). Social personality trait and fitness. -Proc. R. Soc. Lond. B. Biol. Sci. 275:2851-2858.

Cowlishaw, G.U.Y. (1996). Sexual selection and information content in gibbon song bouts. Ethology. 102:272-284.

Dall, S.R. \& Cuthill, I.C. (1997). The information costs of generalism. -Oikos. 80:197-202.

Dall, S.R., Houston, A.I. \& McNamara, J.M. (2004). The behavioural ecology of personality: consistent individual differences from an adaptive perspective. -Ecol. Lett. 7:734-739.

Delgado, R.A. (2006). Sexual selection in the loud calls of male primates: signal content and function. -Int. J. Primatol. 27:5-25.

Dingemanse, N.J. \& Dochtermann, N.A. (2013). Quantifying individual variation in behaviour: mixed-effect modelling approaches. -J. Anim. Ecol. 82:39-54.

Dingemanse, N.J. \& Réale, D. (2005). Natural selection and animal personality. -Behav., 142:1159-1184.

Drent, P.J., van Oers, K. \& van Noordwijk, A.J. (2003). Realized heritability of personalities in the great tit (Parus major). -Proc. R. Soc. Lond. B. Biol. Sci. 270:45-51.

Dupont-Prinet, A., Chatain, B., Grima, L., Vandeputte, M., Claireaux, G. \& McKenzie, D.J. (2010). Physiological mechanisms underlying a trade-off between growth rate and tolerance of feed deprivation in the European sea bass (Dicentrarchus labrax). - J. Exp. Biol. 213:1143-1152. 
Elwood, R.W. \& Briffa, M. (2001). Information gathering and communication during agonistic encounters: A case study of hermit crabs. -Adv. Stud. Behav. 30:53-97

Fresneau, N., Kluen, E., \& Brommer, J. E. (2014). A sex-specific behavioral syndrome in a wild passerine. -Behav. Ecol. 25:359-367.

Garamszegi, L.Z. \& Herczeg, G. (2012). Behavioural syndromes, syndrome deviation and the within-and between-individual components of phenotypic correlations: when reality does not meet statistics. -Behav. Ecol. Sociobiol. 66:1651-1658.

Garamszegi, L. Z., Markó, G., \& Herczeg, G. (2013). A meta-analysis of correlated behaviors with implications for behavioral syndromes: relationships between particular behavioral traits. -Behav. Ecol. art033.

Gosling, S.D. (2001). From mice to men: what can we learn about personality from animal research? -Psychological B. 127:45-86.

Gosling, S.D. \& John, O.P. (1999). Personality dimensions in non-human animals: A crossspecies review. -Curr. Dir. Psychol. Sci. 8:69-75.

Hayes, J.P. \& Jenkins, S.H. (1997). Individual variation in mammals. -J. Mammal. 78:274293.

Hille, S.M. \& Cooper, C.B. (2015). Elevational trends in life histories: revising the pace-oflife framework. -Biol. Rev. 90:204-213.

Jobling, M.A.L.C.O.L.M. (1997). Temperature and growth: modulation of growth rate via temperature change. -In:Seminar series-society for experimental biology. Cambridge University Press, Cambridge, p. 225-254

Ketola, T. \& Kotiaho, J.S. (2012). Inbreeding depression in the effects of body mass on energy use. -Biol. J. Linn. Soc. 105:309-317. 
Killen, S.S., Marras, S. \& McKenzie, D.J. (2011). Fuel, fasting, fear: routine metabolic rate and food deprivation exert synergistic effects on risk-taking in individual juvenile European sea bass. -J. Anim. Ecol. 80:1024-1033.

Krams, I., Kivleniece, I., Kuusik, A., Krama, T., Freeberg, T.M., Mänd, R. \& Mänd, M. (2013). Predation selects for low resting metabolic rate and consistent individual differences in anti-predator behavior in a beetle. -Acta Ethol. 16:163-172.

Lee, Y. \& Nelder, J.A. (1996). Hierarchical generalized linear models. -J. R. Stat. Soc. Ser. B. Stat. Methodol. 58:619-678.

Lee, Y. \& Nelder, J.A. (2006). Double hierarchical generalized linear models (with discussion). -J. R. Stat. Soc. Ser. C Appl. Stat. 55:139-185.

Liberto, R., César, I.I. \& Mesquita-Joanes, F. (2014). Postembryonic growth in two species of freshwater Ostracoda (Crustacea) shows a size-age sigmoid model fit and temperature effects on development time, but no clear temperature-size rule (TSR) pattern. -Limnology. 15:57-67.

McCarthy, I.D. (2000) Temporal repeatability of relative standard metabolic rate in juvenile Atlantic salmon and its relation to life history variation. -J. Fish. Biol., 57:224-238.

MacDonald, S.W., Li, S.C. \& Bäckman, L. (2009). Neural underpinnings of within-person variability in cognitive functioning. -Psychol. Aging. 24:792-808.

Magnhagen, C. \& Borcherding, J. (2008). Risk-taking behaviour in foraging perch: does predation pressure influence age-specific boldness? -Anim. Behav. 75:509-517

Mathot, K.J., \& Dingemanse, N.J. (2015). Energetics and behaviour: a reply to Careau and Garland. -Trends Ecol. Evol. 20:1-2.

Maye, A., Hsieh, C.H., Sugihara, G. \& Brembs, B. (2007). Order in spontaneous behavior. - 
PloS one, 2:e443.

Nakagawa, S., \& Schielzeth, H. (2010). Repeatability for Gaussian and non-Gaussian data: a practical guide for biologists. - Biol. Rev., 85:935-956.

Nespolo, R.F. \& Franco, M. (2007). Whole-animal metabolic rate is a repeatable trait: a meta-analysis. -J. Exp. Bio, 210:2000-2005.

Nesselroade, J.R. (1991). Interindividual differences in intraindividual change. -J. Appl. Psychol. 85:190-210

Niemelä, P.T., Vainikka, A., Hedrick, A.V. \& Kortet, R. (2012). Integrating behaviour with life history: boldness of the field cricket, Gryllus integer, during ontogeny. -Funct. Ecol. $26: 450-456$.

Petersen, J.H. \& Kitchell, J.F. (2001). Climate regimes and water temperature changes in the Columbia River: bioenergetic implications for predators of juvenile salmon. -Can. J. Fis. Aquat. Sci. 58:1831-1841.

Porter, R.K. \& Brand, M.D. (1995). Cellular oxygen consumption depends on body mass. Am. J. Physiol. Regul. Integr. Comp. Physiol., 269:R226-R228.

Ram, N. \& Gerstorf, D. (2009). Time-structured and net intraindividual variability: tools for examining the development of dynamic characteristics and processes. -Psychol. Aging. 24:778-791.

Rankin, C.H., Abrams, T., Barry, R. J., Bhatnagar, S., Clayton, D.F., Colombo, J. Coppola, G., Geyer, M.A., Glanzman, D.L., Marsland, S., McSweeney, F.K., Wilson, D.A., Wu, C., Thompson, R.F., Clayton, D. \& McSweeney, F. K. (2009). Habituation revisited: an updated and revised description of the behavioral characteristics of habituation. Neurobiol. Learn. Mem. 92:135-138.

Raderschall, C.A., Magrath, R.D., Hemmi, J.M. (2011) Habituation under natural conditions: 
model predators are distinguished by approach direction. -J. Exp. Biol. 214:4209-4216.

Réale, D., Dingemanse, N.J., Kazem, A.J. \& Wright, J. (2010). Evolutionary and ecological approaches to the study of personality. -Proc. R. Soc. Lond. B. Biol. Sci. 365:3937-3946

Réale, D., Reader, S.M., Sol, D., McDougall, P.T. \& Dingemanse, N.J. (2007). Integrating animal temperament within ecology and evolution. -Biol. Rev. 82:291-318.

Rogers, T.L. \& Cato, D.H. (2002). Individual variation in the acoustic behaviour of the adult male leopard seal, Hydrurga leptonyx. -Behaviour. 139:1267-1286.

Salthouse, T.A. (2007). Implications of within-person variability in cognitive and neuropsychological functioning for the interpretation of change. -Neuropsychology. 2:401411.

Schürch, R. \& Heg, D. (2010). Life history and behavioral type in the highly social cichlid Neolamprologus pulcher. -Behav. Ecol. 21:588-598.

Siegler, R.S. (1994). Cognitive variability: A key to understanding cognitive development. Current directions in psychological science, 1-5.

Sih, A. \& Bell, A.M. (2008). Insights for behavioral ecology from behavioral syndromes. Adv. Stud. Behav. 38:227-281.

Sih, A., Bell, A. \& Johnson, J.C. (2004). Behavioral syndromes: an ecological and evolutionary overview. -Trends Ecol. Evol. 19:372-378.

Smith, B.R. \& Blumstein, D.T. (2008). Fitness consequences of personality: a meta-analysis. -Behav. Ecol. 19:448-455.

Stamps, J.A., Briffa, M. \& Biro, P.A. (2012). Unpredictable animals: individual differences in intraindividual variability (IIV). -Anim. Behav. 83:1325-1334.

Stearns S. C. (1992) The evolution of life histories. Oxford University Press, Oxford, UK. 
Stevens, E. D. (1992). Use of plastic materials in oxygen-measuring systems. -J. Appl. Physiol. 72:801-804.

Sundt-Hansen, L., Neregård, L., Einum, S., Höjesjö, J., Björnsson, B.T., Hindar, K., Økland, F. \& Johnsson, J.I. ( 2009 ) Growth enhanced brown trout show increased movement activity in the wild. -Fun, Ecol., 23:551-558.

Thorpe, W.H. (1956). Learning and instinct in animals. Methuen, London.

Urszán, T.J., Garamszegi, L.Z., Nagy, G., Hettyey, A., Török, J. \& Herczeg, G. (2015a). No personality without experience? A test on Rana dalmatina tadpoles. -Ecol. Evol. 5:58475856.

Urszán, T.J., Török, J., Hettyey, A., Garamszegi, L.Z. \& Herczeg, G. (2015b). Behavioural consistency and life history of Rana dalmatina tadpoles. -Oecologia, 178:129-140.

Widdows, J. \& Staff, F. (2006). Biological effects of contaminants: measurement of scope for growth in mussels. -International Council for the Exploration of the Sea, 40:1-30

Wilson, A.J., Reale, D., Clements, M.N., Morrissey, M.M., Postma, E., Walling, C.A., Kruuk, L.E.B. \& Nussey, D.H. (2010). An ecologist's guide to the animal model. -J. Anim. Ecol. 79:13-26. 